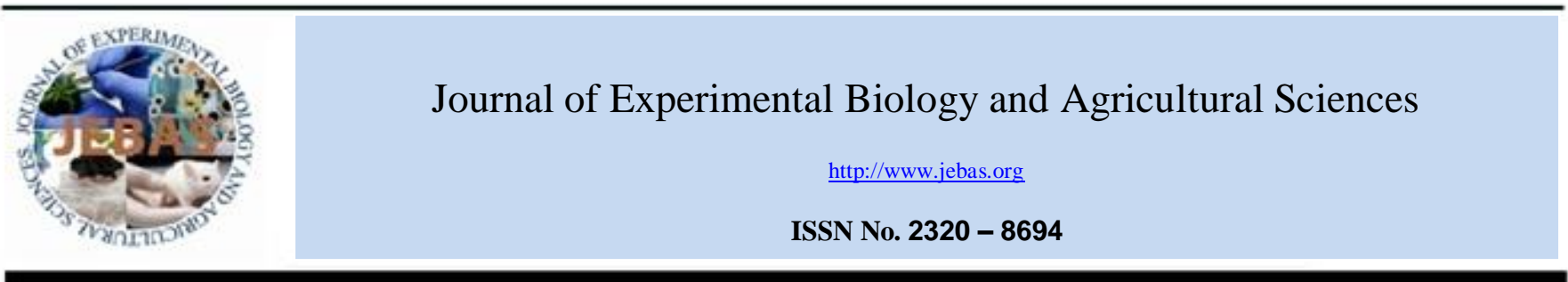

\title{
EVALUATION OF THE EFFICACY OF POLYHERBAL ANTI-STRESSOR PRODUCT (RESTOBAL) AGAINST STRESS INDUCED BY Balantidium coli INFECTION IN BUFFALOES
}

\author{
S.Sivajothi ${ }^{1}$, B.Sudhakara Reddy ${ }^{2}$, Y.V.Prithvidhar Reddy ${ }^{3}$, S.Vani ${ }^{4}$, \\ Kotagiri Ravikanth ${ }^{5}$, Bhaskar Ganguly ${ }^{6}$
}

\footnotetext{
${ }^{1}$ Assistant Professor, Department of Veterinary Parasitology, College of Veterinary Science, Proddatur- 516 360, Y.S.R. Kadapa District, Sri Venkateswara Veterinary University, Andhra Pradesh, India

${ }^{2}$ Assistant Professor, Faculty of Veterinary Medicine, Department of Veterinary Clinical Complex, College of Veterinary Science, Proddatur- 516 360, Y.S.R. Kadapa District, Sri Venkateswara Veterinary University, Andhra Pradesh, India

${ }^{3}$ Assistant Professor, Department of Veterinary Clinical Complex, College of Veterinary Science, Proddatur- 516 360, Y.S.R. Kadapa District, Sri Venkateswara Veterinary University, Andhra Pradesh, India

${ }^{4}$ Assistant Professor, Department of Animal Genetics and Breeding, College of Veterinary Science, Proddatur- 516 360, Y.S.R. Kadapa District, Sri Venkateswara Veterinary University, Andhra Pradesh, India

${ }^{5}$ Director, Operations and Research, Ayurvet Limited, Village: Katha, Baddi - 173205, Himachal Pradesh

${ }^{6}$ Senior Scientist and Head, Clinical Research, Ayurvet Limited, Village: Katha, Baddi - 173205, Himachal Pradesh
}

Received - June 12, 2018; Revision - August 20, 2018; Accepted - September 25, 2018

Available Online - October 5, 2018

DOI: http://dx.doi.org/10.18006/2018.6(5).879.883

KEYWORDS
Stress
Disease
Buffaloes
Restobal
Balantidium coli

* Corresponding author

E-mail: sivajothi579@gmail.com (S.Sivajothi)

Peer review under responsibility of Journal of Experimental Biology and Agricultural Sciences.

Production and Hosting by Horizon Publisher India [HPI] (http://www.horizonpublisherindia.in/).

All rights reserved.

\begin{abstract}
The present study was conducted to determine the alterations in haematological parameters and stress markers in naturally Balantidium coli infected buffaloes, along with this efficacy of polyherbal antistressor product Restobal (Restobal ${ }^{\circledR}, \mathrm{M} / \mathrm{s}$ Ayurvet Limited) was also evaluated against the stress induced by $B$. coli. In present study, a total of ten apparently healthy buffaloes were selected and considered as control group while twenty buffaloes with natural $B$. coli infection were included in the disease group and considered for treatment trial. In all the clinical cases, clinical examination and detailed appraisal of haemato-biochemical profiles were carried out. For treatment trial, a total of twenty diseased buffaloes were divided into two groups with ten buffaloes in each group. In therapeutic trials (group I) buffaloes were administered with specific medication against $B$. coli infection and in herbal trail buffaloes (group II) were administered with specific medication against $B$. coli infection along with
\end{abstract}

All the article published by Journal of Experimental Biology and Agricultural Sciences is licensed under a Creative Commons Attribution-NonCommercial 4.0 International License Based on a work at www.jebas.org.

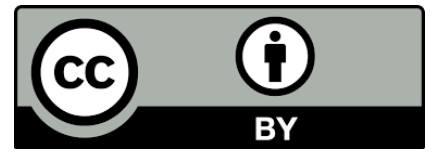


the commercial polyherbal anti stressor product (Restobal). Findings of present study revealed that buffaloes with $B$. coli infection have reduced haemoglobin levels, total erythrocyte count and monocyte count with increased total leukocyte, neutrophil, lymphocyte, eosinophil count and serum cortisol levels than the apparently healthy buffaloes which indicative of stress due to disease. Buffaloes administered with oral polyherbal anti stressors product showed the significant difference from the group I by elevation of haemoglobin parameters, packed cell volume and serum cortisol levels along with variations in the vital parameters. In conclusion, polyherbal anti stressor product which contains Ocimum sanctum, Phyllanthus emblica, Mangifera indica and Withania somnifera can be recommended along with the specific disease therapeutic protocol in buffaloes to the management of disease induced stress.

\section{Introduction}

Protozoan diseases have economic importance in ruminants and other animals. Among the different protozoan diseases, balantidiasis (Balantidium coli infection) is a common disease of ruminants including cattle and buffaloes. It usually presents in the apparently healthy animals but under certain circumstances, it also causes clinical diseases in bovines (Sivajothi \& Reddy, 2018). During the pathogenesis, it produces the hyaluronidase which potentially enhancing the ability of parasites to invade the mucosa further causes passing of watery persistent foetid dung, dehydration, loss of body condition and leads to the development of stress (Roy et al., 2011). During the period of stress, excessive levels of cortisol will be released which causes impaired regular functions of host and various endocrinal responses. Management of stress is essential to maintain the regular production and reproduction in animals. Studies on the management of stress during the disease conditions are very limited (Schuster \& Ramirez, 2008). In previous literature, the efficacy of the herbal product reported as supportive therapy during the vaccination stress in buffaloes (Sivajothi et al., 2018a; Sivajothi et al., 2018b). Hence, the present study was conducted to evaluate the stress parameters in buffaloes with clinical disease and efficacy of the polyherbal anti-stressor product (Restobal ${ }^{\circledR}, \mathrm{M} / \mathrm{s}$ Ayurvet Limited) which contains Ocimum sanctum, Phyllanthus emblica, Mangifera indica and Withania somnifera against the management of stress caused by Balantidium coli the disease in buffaloes.

\section{Materials and Methods}

\subsection{Experimental Animals}

The present study was conducted at College of Veterinary Science, Proddatur, YSR Kadapa District of Andhra Pradesh, India. For present study, a total of ten apparently healthy buffaloes were selected and considered as a control group to compare the haematological parameters in diseased buffaloes. Twenty buffaloes with natural $B$. coli infection were included in the disease group and separated into two groups equally. Buffaloes in group I were treated for specific B. coli infection alone and buffaloes in groups II were treated for $B$. coli infection along with administration of oral polyherbal anti stressor preparation (Restobal $^{\circledR}, \mathrm{M} / \mathrm{s}$ Ayurvet Limited @ $50 \mathrm{ml}$ orally BID).

\subsection{Clinical examination}

A detailed clinical and physical examination of the individual buffalo was carried out in both groups of buffaloes. Blood samples were collected from the buffaloes in both the groups on the $0^{\text {th }}$ day, $3^{\text {rd }}$ day and $5^{\text {th }}$ day of post treatment. Three $\mathrm{ml}$ of whole blood with disodium ethylene diamine tetracetic acid (EDTA) was collected for haemogram and five $\mathrm{ml}$ of blood was collected into the vial containing clot activator for serum separation for estimation of serum cortisol levels.

\subsection{Laboratory analysis}

Whole blood sample was utilized for the estimation of red blood cell count (RBC), haemoglobin concentration $(\mathrm{Hb})$, packed cell volume (PCV), total leukocyte count (TLC) and differential leukocyte counts (DLC) and serum was utilized for the estimation of cortisol by the standard procedures according to the test kit (Feldman et al., 2000).

\subsection{Study Analysis}

B. coli infection was diagnosed by the demonstration of the both trophozoites and cysts of $B$. coli in dung samples. Clinically diseased buffaloes were showed reduced feed and water intake, passing of watery and foul smell dung mixed with blood and drastic reduction in the milk yield. Daily feed intake and leftover feed by the individual animal and milk production were recorded throughout the study period.

\subsection{Treatment}

Buffaloes with clinical B. coli infection in both the groups were treated with injection oxytetracycline @ $10 \mathrm{mg} / \mathrm{kg}$ body weight, intravenously, BID for three days; injection meloxicam @ 0.5 
$\mathrm{mg} / \mathrm{kg}$ body weight intramuscularly once; injection metronidazole @ $20 \mathrm{mg} / \mathrm{kg}$ body weight intravenously BID; intravenous fluids were administered (@10 ml mg/kg body weight) for three days and oral bolus containing metronidazole and furazolidone was given twice in a day for seven days (Sivajothi \& Reddy, 2018).

\subsection{Statistical analysis}

Recorded data were presented as the mean \pm standard error (SE) and subjected to statistical analysis using student's $\mathrm{t}$ - test and one - way analysis of variance by using SPSS version 20.0. If P > 0.05 considered as statistically not significant, $\mathrm{P} \leq 0.05$ considered as statistically significant and $\mathrm{P} \leq 0.01$ considered as statistically highly significant at $95 \%$ level of significance.

\section{Results}

\subsection{Clinical and laboratory findings in diseased buffaloes}

Findings of present study revealed that buffaloes with $B$. coli infection showed elevated vital parameters including rectal temperature, heart rate and pulse rate. All the buffaloes with clinical diseases had reduced milk production (50 to $80 \%$ of the initial production). Haematology revealed reduced haemoglobin levels, total erythrocyte count and monocyte count with increased total leukocyte, neutrophil, lymphocyte, eosinophil count and serum cortisol levels than the apparently healthy buffaloes.
Clinical, haematological changes during the disease stress were mentioned in Table 1.

\subsection{Clinical and laboratory findings in group I and group II}

Observed clinical, haematological, cortisol levels in group I and group II of buffaloes were presented in Table 2. Buffaloes in the group II showed significant variation from the group I buffaloes i.e. elevated levels of haemoglobin and reduction in the packed cell volume; reduction in the serum cortisol levels; reduction in the heart rate, pulse rate and respiratory rate of the individual buffaloes.

\section{Discussions}

Variations in the diseased buffaloes suggested that B. coli infection induces changes in vital, haematological biochemical parameters and stress markers which are indication of stress due to disease. Recorded abnormal haematological findings were in association with the previous findings and suggestive of stress due to disease in buffaloes (Schuster \& Ramirez, 2008; Sivajothi \& Reddy, 2017). In both the groups of buffaloes, reduction in the daily feed intake was noticed as a common finding and leftover roughage was noticed throughout the study period and there is no variation in between the groups during the trial period. All the buffaloes with clinical $B$. coli infection responded well to the given therapy. The response in the activity, consistency of the

Table 1 Mean vital, haematological and cortisol levels in buffaloes with stress due to Balantidium coli infection

\begin{tabular}{|c|c|c|c|c|}
\hline $\begin{array}{c}\text { S. } \\
\text { No }\end{array}$ & Parameters & $\begin{array}{l}\text { Apparently healthy buffaloes } \\
\text { (Control group) } \\
(\mathrm{n}=10)\end{array}$ & $\begin{array}{l}\text { Buffaloes with } B \text { coli infection } \\
\text { (Disease group) } \\
(\mathrm{n}=20)\end{array}$ & P - Value \\
\hline 1 & Haemoglobin (g/dL) & $11.27 \pm 0.13$ & $9.42 \pm 0.36$ & $0.001 * * *$ \\
\hline 2 & $\operatorname{PCV}(\%)$ & $36.50 \pm 1.1$ & $39.95 \pm 2.60$ & $0.004 * *$ \\
\hline 3 & TEC $\times 10^{6} / \mathrm{cumm}$ & $7.45 \pm 0.09$ & $5.40 \pm 0.12$ & $0.001^{* * *}$ \\
\hline 4 & TLC /cumm & $8378.0 \pm 236.1$ & $9503.7 \pm 289.6$ & $0.001^{* *}$ \\
\hline 5 & Neutrophils /cumm & $2555.6 \pm 101.22$ & $2729.80 \pm 94.54$ & $0.010^{*}$ \\
\hline 6 & Lymphocytes /cumm & $5227.87 \pm 201.21$ & $6186.5 \pm 191.2$ & $0.006^{* *}$ \\
\hline 7 & Monocytes /cumm & $293.3 \pm 19.3$ & $213.8 \pm 31.46$ & $0.000 * * *$ \\
\hline 8 & Eosinophils /cumm & $192.70 \pm 9.16$ & $313.6 \pm 19.24$ & $0.001 * *$ \\
\hline 9 & Basophil /cumm & $67.60 \pm 9.22$ & $59.86 \pm 6.02$ & $0.205^{\mathrm{NS}}$ \\
\hline 10 & Cortisol (nmol/L) & $18.91 \pm 0.72$ & $48.49 \pm 1.35$ & $0.000^{* *}$ \\
\hline 11 & Temperature $\left({ }^{\circ} \mathrm{F}\right)$ & $99.81 \pm 0.05$ & $100.44 \pm 0.15$ & $0.001^{* *}$ \\
\hline 12 & Heart rate $(/ \mathrm{min})$ & $63.75 \pm 0.94$ & $77.60 \pm 1.15$ & $0.001 * *$ \\
\hline 13 & Pulse rate (/min) & $63.05 \pm 0.73$ & $76.00 \pm 1.15$ & $0.001 * *$ \\
\hline 14 & Respiratory rate $(/ \mathrm{min})$ & $17.10 \pm 0.46$ & $19.95 \pm 0.62$ & $0.001 * *$ \\
\hline
\end{tabular}

Value given in different rows are Mean \pm S.E.

Journal of Experimental Biology and Agricultural Sciences http://www.jebas.org 
Table - 2 Mean vital, haematological and cortisol levels in both the group of buffaloes

\begin{tabular}{|c|c|c|c|c|c|c|c|c|}
\hline \multirow{2}{*}{$\begin{array}{l}\text { S. } \\
\text { No. }\end{array}$} & \multirow{2}{*}{ Parameters } & \multicolumn{2}{|c|}{$0^{\text {th }}$ Day } & \multicolumn{2}{|c|}{$3^{\text {rd }}$ Day } & \multicolumn{2}{|c|}{$5^{\text {th }}$ Day } & \multirow{2}{*}{$\begin{array}{c}\mathrm{P} \\
\text { value }\end{array}$} \\
\hline & & Group I & Group II & Group I & Group II & Group I & Group II & \\
\hline 1 & Haemoglobin $(\mathrm{g} / \mathrm{dL})$ & $9.51 \pm 0.17$ & $9.39 \pm 0.26$ & $9.62 \pm 0.13$ & $9.55 \pm 0.24$ & $9.86 \pm 0.19$ & $10.43 \pm 0.16$ & $0.030 *$ \\
\hline 2 & $\operatorname{PCV}(\%)$ & $40.2 \pm 0.74$ & $39.8 \pm 0.57$ & $38.9 \pm 0.61$ & $36.75 \pm 0.81$ & $37.35 \pm 0.55$ & $32.1 \pm 0.73$ & $0.001^{* *}$ \\
\hline 3 & TEC $\times 10^{6} /$ cumm & $5.51 \pm 0.09$ & $5.32 \pm 0.14$ & $5.53 \pm 0.09$ & $5.34 \pm 0.12$ & $5.54 \pm 0.1$ & $5.40 \pm 0.13$ & $0.390^{\mathrm{NS}}$ \\
\hline 4 & TLC /cumm & $9434.6 \pm 580.6$ & $9573.6 \pm 196.9$ & $9337.8 \pm 498.8$ & $9569.4 \pm 297.5$ & $8394.8 \pm 840.7$ & $8921.6 \pm 120.6$ & $0.560^{\mathrm{NS}}$ \\
\hline 5 & Neutrophils /cumm & $2594.35 \pm 102.7$ & $2766.59 \pm 120.9$ & $2567.67 \pm 119.4$ & $2765.45 \pm 218.6$ & $2451.04 \pm 186.4$ & $2720.9 \pm 119.4$ & $0.660^{\mathrm{NS}}$ \\
\hline 6 & Lymphocytes/cumm & $6198.27 \pm 980.4$ & $6193.74 \pm 162.74$ & $6115.73 \pm 302.4$ & $6229.42 \pm 367.7$ & $5430.91 \pm 288.2$ & $5673.75 \pm 218.4$ & $0.080^{\mathrm{NS}}$ \\
\hline 7 & Monocytes /cumm & $235.85 \pm 80.23$ & $191.46 \pm 21.14$ & $224.08 \pm 26.16$ & $181.8 \pm 32.18$ & $184.67 \pm 31.2$ & $160.57 \pm 39.3$ & $0.130^{\mathrm{NS}}$ \\
\hline 8 & Eosinophils /cumm & $339.62 \pm 21.4$ & $287.19 \pm 9.29$ & $326.79 \pm 16.34$ & $267.89 \pm 30.29$ & $243.42 \pm 24.31$ & $249.78 \pm 16.9$ & $0.810^{\mathrm{NS}}$ \\
\hline 9 & Basophil/cumm & $66.03 \pm 11.15$ & $47.86 \pm 7.16$ & $65.35 \pm 9.15$ & $47.84 \pm 8.17$ & $58.75 \pm 12.15$ & $53.52 \pm 9.16$ & $0.660^{\mathrm{NS}}$ \\
\hline 10 & Cortisol $(\mathrm{nmol} / \mathrm{L})$ & $48.07 \pm 2.24$ & $48.99 \pm 1.16$ & $46.5 \pm 2.09$ & $41.75 \pm 1.98$ & $45.4 \pm 1.58$ & $33.8 \pm 1.49$ & 0.000 ** \\
\hline 11 & Temperature $\left({ }^{\circ} \mathrm{F}\right)$ & $100.7 \pm 0.19$ & $100.1 \pm 0.19$ & $100.3 \pm 0.16$ & $100.0 \pm 0.15$ & $99.8 \pm 0.16$ & $99.3 \pm 0.41$ & $0.292^{\mathrm{NS}}$ \\
\hline 12 & Heart rate & $77.6 \pm 1.7$ & $77.6 \pm 1.6$ & $76.1 \pm 1.07$ & $74.8 \pm 1.07$ & $73.1 \pm 2.36$ & $66.7 \pm 1.73$ & $0.043 *$ \\
\hline 13 & Pulse rate & $75.7 \pm 1.33$ & $76.3 \pm 1.30$ & $74.5 \pm 1.23$ & $74.3 \pm 1.13$ & $72.5 \pm 1.99$ & $65.0 \pm 1.3$ & $0.006 *$ \\
\hline 14 & Respiratory rate & $19.6 \pm 0.9$ & $20.3 \pm 0.89$ & $18.4 \pm 0.56$ & $18.7 \pm 0.56$ & $18.1 \pm 0.7$ & $16.5 \pm 0.30$ & $0.048 *$ \\
\hline
\end{tabular}

Value given in different rows are Mean \pm S.E.

dung, reduction in the frequency of dung was improved by the third day of therapy and total duration required to attain the normal state of the animals was four to eight days. After therapy, buffaloes showed increased haemoglobin, reduced packed cell volume, total leukocyte count, lymphocyte count and cortisol levels (Padgett \& Glaser, 2003).

Protozoan diseases cause anaemia in bovines in association with the dysentery (Reddy et al., 2015). Transmission of the B. coli infection occurs through the ingestion of food or water contaminated with cysts of Balantidium sp. It affects the small and large intestine and causes mainly by invading the colon and asymptomatic to serious dysentery (Ahmad \& Rasad, 2011). Diagnosis of balantidiasis is done by demonstration of any of the development stages including cysts or trophozoites in dung (Sudan et al., 2012). During the disease management, the therapeutic efficacy of the different drugs mainly determined on the basis of the disappearance of clinical signs and reduction of cysts/trophozoites in dung. The therapeutic efficacies of various drugs like nitro heterocyclic compounds, secnidazole, metronidazole, benznidazole and furazolidone have been documented against B. coli (Tarrar et al., 2008).

Stress causes different changes in neurotransmitter activity which results in a cascade of hormonal release from the hypothalamus pituitary adrenal (HPA) axis resulting in an increase in blood corticosterone levels which in turn lead to an increase in serum triglycerides levels and hyperglycemia (Kumar et al., 2013). Stress is a reflex reaction revealed by the inability of an animal to cope with its environment, to the unfavourable conditions. Stress had the impact on growth, production, reproduction and susceptibility to other diseases (Yang \& Glaser, 2000). The polyherbal product utilized in the present study was Restobal ${ }^{\circledR}$ (M/s Ayurvet Limited) which contains O. sanctum, P. emblica, $M$. indica and W. somnifera etc. Medicinal properties of these plant materials are well reported by various researchers (Kumar et al., 2012; Prakash et al., 2012; Sharma et al., 2013). These plant materials have strong anti-stress, antioxidant haemopoeitic and rejuvenating properties. Further, an increase in antioxidant defence, that is, enzymes SOD, CAT and ascorbic acid has been also well document, whereas a significant decrease in lipid peroxidation was also reported. Changes in these parameters proved that the buffaloes with restobal treatment were free from stress. Restobal is recommended to the buffaloes with the specific disease and it can be used as adjuvant therapy to enhance the speed of recovery as well as to quickly attain normal health status.

\section{Conclusion}

The present study reports B. coli infection in buffaloes and higher level of stress markers was also reported during the infection. Result of study suggests the use of polyherbal anti stressor 
product Restobal $^{\circledR}$ (M/s Ayurvet Limited), as an adjuvant therapy for the management of stress developed due to $B$. Coli infection in buffaloes.

\section{Acknowledgement:}

The authors are thankful to the authorities of Sri Venkateswara Veterinary University for providing the facilities to carry out the work.

\section{Conflicts of interest}

No conflicts of interests are declared by authors for the contents in this manuscript.

\section{References}

Ahmad MF, Rasad R (2011) Balantidium coli. Medical Parasitology 4th Ed. Jakarta: Faculty of Medicine, University of Indonesia.

Feldman BF, Zinkl JG, Jain NC (2000) Schalms Veterinary Haematology. 5th Edition, Williams and Wilkins, Philadelphia: 21-100.

Kumar A, Singh A, Dora J (2012) Essential perspectives for Emblica officinalis. International Journal of Pharmaceutical and Chemical Sciences 1:11-18.

Padgett DA, Glaser R (2003) How stress influences the immune response. Trends in Immunology 24: 444-448.

Kumar CP, Rawath SS, Kumar YD, Neelima KSSN (2013) Effect of Emblica Officinalis on stress induced biochemical and psychological changes in mice. Global Journal of Medical Research Veterinary Science and Veterinary Medicine 13: 25-28.

Prakash D, Upadhyay G, Gupta C, Pushpangadan P, Singh KK (2012) Antioxidant and free radical scavenging activities of some promising wild edible fruits. International Food Research Journal 19:1109-16.

Reddy BS, Sivajothi S, Rayulu VC (2015) Clinical coccidiosis in adult cattle. Journal of Parasitic Diseases 39: 557-559.

Roy BC, Mondal MMH, Talukder MH, Majumder S (2011)
Prevalence of Balantidium coli in buffaloes at different areas of Mymensingh. Journal of Bangladesh Agricultural University 9 : 67-72.

Schuster FL, Ramirez AL (2008) Current world status of Balantidium coli. Clinical Microbiological Review 21: 626-38.

Sharma V, Agrawal RC, Pandey S (2013) Phytochemical screening and determination of anti-bacterial and antioxidant potential of Glycyrrhiza glabra root extracts. Journal of Environment Research and Development 7 :1552-1558.

Sivajothi S, Reddy BS (2017) Antioxidant status and electrocardiographic changes in buffaloes with Trypanosoma evansi infection. Chemical Science Review and Letters 6: 25732576.

Sivajothi S, Reddy BS (2018) Acute fulminating form of Balantidium coli infection in buffaloes. Research \& Reviews: Research Journal of Biology 6: 17-19.

Sivajothi S, Reddy YVP, Reddy BS, Vani S, Chandel S, Ravikanth K, Ganguly B (2018a) Evaluation of herbal antistressor product (Restobal) during the vaccination stress in buffaloes. International Journal of Current Microbiology and Applied Sciences 7 : 723-727.

Sivajothi S, Reddy BS, Reddy YVP, Vani S, Chandel S, Ravikanth K, Ganguly B (2018b) Assessment of summer stress and management with poly herbal anti-stressor product (restobal) in buffaloes. Journal of Animal Research 8 : 713-717.

Sudan V, Sharma RL, Patya A, Singh PK (2012) An occurrence of clinical balantidiasis in a cross bred cow and its therapeutic management. Journal of Veterinary Parasitology 26: 164-66.

Tarrar MA, Khan MS, Pervez K, Ashraf K, Khan JA, Rehman ZU (2008) Detection and chemotherapy of Balantidium coli in buffaloes around Lahore, Pakistan. Pakistan Journal of Agricultural Sciences 45: 163-166.

Yang EV, Glaser R (2000) Stress-induced immunomodulation: impact on immune defenses against infectious disease. Biomedicine \& Pharmacotherapy 54: 245-250. 